\title{
O Papel de Condutores Ambientais Locais e de Cursos de Capacitação no Ecodesenvolvimento Turístico e as Expectativas Sociais no Sul do Brasil
}

\author{
The Role of Local Environmental Conductors and Training Courses in the Tourism Eco- \\ development and Social Expectations in Southern Brazil
}

\section{El Papel de los Conductores Ambientales Locales y de los Cursos de Formación em el Eco- desarrollo Turístico y las Expectativas Sociales en el Sur de Brasil}

\author{
Liz Cristina Camargo Ribas ${ }^{1}$
}

Claudia Hickenbick ${ }^{2} 3$

\begin{abstract}
Resumo
Quem é o condutor ambiental local e qual é a sua função frente à natureza, ao turismo e à sociedade? Estas são questões primordiais que norteiam a estruturação e a execução de cursos de capacitação profissional para esse perfil, influenciando tanto a visão da sociedade sobre o profissional "condutor" como sua contribuição na conservação e preservação ambiental. Apesar de existirem recomendações referentes à carga horária, eixos temáticos e conteúdos mínimos a serem ministrados em cursos de capacitação para esse perfil, a concepção do "sujeito" condutor normalmente não é explicitada ou detalhada. O presente trabalho visa apresentar uma reflexão e uma perspectiva para essa lacuna referencial, baseando-se na vivência de práticas de capacitação de condutores ambientais no sul do Brasil pelo Instituto Federal de Santa Catarina. O trabalho também visa enfatizar o papel dos condutores ambientais no ecodesenvolvimento turístico, bem como apresentar expectativas de diferentes agentes sociais e relatos de condutores após cursos de capacitação.
\end{abstract}

Palavras-chave: condutor ambiental; ecoturismo; formação profissional; turismo de base comunitária; unidades de conservação.

\footnotetext{
1 Bacharel e Licenciada em Ciências Biológicas (UFSC) e Mestre em Biotecnologia Ambiental (UFSC). Professora de Educação Ambiental do Campus Florianópolis-Continente do IF-SC, atuante em cursos de qualificação profissional de condutores ambientais locais. Coordenadora da Incubadora de Empreendimentos com base na Economia Solidária do CFC/ IF-SC. E-mail: lizribas@ifsc.edu.br.

${ }^{2}$ Licenciada em História (UNIVALI), Especialista em Historiografia Geral e do Brasil (UNIVALI) e Mestre em Educação (UFPR). Professora de História e Ciências Humanas do Campus Florianópolis-Continente do IF-SC, atuante em cursos de qualificação profissional de condutores ambientais locais. Coordenadora da Incubadora de Empreendimentos com base na Economia Solidária do CFC/ IF-SC. E-mail: claudia@ifsc.edu.br.

${ }^{3}$ As autoras do presente trabalho consideram como co-autores os seguintes agentes sociais locais: representantes comunitários (Ademar Alarício do Espírito Santo, Fabrício Gonçalves;); representantes de órgãos públicos ligados ao meio ambiente (Danilo da Silva Funke/FLORAM; Eduardo Mussatto/FATMA), turismo (Gicele Truppel/SETUR-Palhoça) e educação (Luiz Otávio Cabral/IF-SC); condutores ambientais locais (Altamiro Valverde Filho; Luana Wirth; Maria de Lourdes Prá da Silva; Maria José Passareli Madureira; Pércio Renato Souza dos Santos; Rodrigo Ramirez).
} 


\begin{abstract}
Who is the local environmental conductor and what is his/her role toward nature, tourism and society? These are fundamental questions that guide the structuring and implementation of professional training courses for this profile that influences both the view of society on the professional "conductor" and his/her contribution to conservation and environmental protection as well. Although there are recommendations regarding the duration, themes and minimum contents to be taught in training courses for conductors, the concept of "conductor subject" is usually not explicit or detailed. The present work discusses and presents an outlook for this reference gap, based on the experience of practical training of environmental conductors in the southern Brazil by the Instituto Federal de Santa Catarina. This work also aims to emphasize the role of environmental conductors in tourism eco-development, as well as present the expectations of different "social actors" and conductor reports after their training courses.
\end{abstract}

Keywords: environmental conductor; ecotourism; professional training; community-based tourism; protected natural environments.

\title{
Resumen
}

¿Quién es el conductor ambiental local y cuál es su función hacia la naturaleza, el turismo y la sociedad? Esas son preguntas fundamentales que guían la estructuración e implementación de cursos de formación profesional para ese perfil, influenciando tanto la visión de la sociedad sobre el profesional "conductor" como su contribución a la conservación y protección del medio ambiente. Aunque existan recomendaciones sobre los temas y contenidos mínimos para los cursos de formación dirigidos a ese perfil profesional, el concepto de "sujeto" conductor no suele ser explícito o detallado. Este trabajo presenta un análisis y una perspectiva para esa laguna referencial, basada en la experiencia de la formación práctica de los conductores ambientales en el sur de Brasil, por el Instituto Federal de Santa Catarina. El trabajo también pretende hacer hincapié en el papel de los conductores ambientales para el eco-desarrollo del turismo, así como presentar las expectativas de diferentes agentes sociales y relatos de los conductores que pasaron por la formación profesional.

Palabras clave: conductor ambiental; ecoturismo; formación profesional; turismo de base comunitaria; ambientes naturales protegidos.

\section{Introdução}

A promoção de cursos de capacitação de condutores ambientais locais e o seu reconhecimento e regulamentação ainda são incipientes no Brasil. Contudo, essas ações apresentam perspectivas promissoras, especialmente quando se analise o potencial ecoturístico e a biodiversidade do país. 
Conforme o Ministério do Meio Ambiente (MMA/BRASIL, 2011), experiências de ecoturismo de base comunitária estão dando seus primeiros passos em território nacional. Para que se consolidem como atividade econômica viável, dependem de políticas públicas que valorizem os conhecimentos, saberes e tradições das comunidades, e estimulem o empreendedorismo social no processo de transformação da rica sociobiodiversidade em produtos ecoturísticos com a "cara" do Brasil.

De acordo com registros, relatórios e alguns artigos publicados (FERREIRA; COUTINHO, 2010; MMA/PROECOTUR, 2009; MMA/BRASIL, 2006), constata-se que a partir de 2001 o Ministério do Meio Ambiente intensifica ações em prol da capacitação ecoturística no país, através do Programa de Apoio ao Ecoturismo e à Sustentabilidade Ambiental no Turismo (PROECOTUR). Entre os anos de 2001 e 2003 foram promovidos pelo Programa oficinas de sensibilização em diversas localidades - especialmente em estados nortistas. Ressalta-se que oficinas de capacitação em ecoturismo com envolvimento do Ministério ocorreram também antes do Programa, em todo o território nacional, especialmente entre os anos de 1994 e 1997 - período no qual são registrados aproximadamente 960 agentes capacitados.

Ações de capacitação em ecoturismo e formações de condutores ambientais locais pelo PROECOTUR/MMA iniciam efetivamente em 2005. Entretanto, apenas em 2008 esses profissionais passam a ser regulamentados em nível federal, através da Instrução Normativa 08/2008 do ICMBio (Instituto Chico Mendes de Conservação da Biodiversidade), a qual estabelece normas e procedimentos para a prestação de serviços vinculados à visitação e ao turismo em Unidades de Conservação Federais por condutores de visitantes. A partir dessa Instrução Normativa (IN), órgãos públicos estaduais e municipais passaram a vislumbrar a possibilidade de regulamentar a atuação de condutores localmente. Um exemplo concreto pode ser verificado na capital do estado de Santa Catarina - Florianópolis, onde a Fundação Municipal do Meio Ambiente (FLORAM) regulamentou a atuação desses profissionais dentro de unidades de conservação municipais, através da IN 001/2010. O estabelecimento dessa IN não foi uma ação isolada, mas resultado de articulações interinstitucionais entre órgãos ambientais (FLORAM; FATMA - Fundação Estadual do Meio Ambiente de Santa Catarina), turísticos (Secretarias de Turismo de Florianópolis e de Palhoça/SC) e educacionais (IF-SC - 
Campus Florianópolis-Continente), garantindo a capacitação contínua de condutores e o seu reconhecimento e credenciamento local, possibilitando sua consolidação profissional.

Ressalta-se que já em 2008 o condutor passa a ser visto como um profissional do eixo do turismo, ligado ao meio ambiente e capacitado por instituições de ensino. Por esse motivo, articulações entre os Ministérios do Turismo (MTur), do Meio Ambiente (MMA) e da Educação (MEC) se intensificam, na tentativa de regulamentar a atuação e capacitação desse profissional (FERREIRA, 2008; MTur/BRASIL, 2008). Dentro desse contexto, os Institutos Federais de Educação, Ciência e Tecnologia (IFs) foram incentivados pelo MMA - com apoio do MTur e MEC - para atuarem na capacitação de condutores. O Campus FlorianópolisContinente (IF-SC), que trabalha exclusivamente dentro do eixo de Turismo e Hospitalidade, envolveu-se com a ideia, formando a primeira turma de condutores ambientais para a Ilha de Santa Catarina em 2010. A partir desta formação, outros Campi do IF-SC passaram a capacitar ou estruturar cursos de qualificação de condutores, como o Campus Itajaí e o Campus Avançado Urupema.

Apesar da capacitação de condutores ser uma prática em vias de consolidação no Brasil, a concepção do "sujeito" condutor não é explicitada ou referenciada detalhadamente. Quais as ações e princípios esperados desses profissionais que os caracterizam como condutores? Como eles podem promover o ecodesenvolvimento turístico local? Quais são as expectativas sociais sobre esses profissionais? O presente trabalho visa apresentar uma reflexão e uma perspectiva para essa lacuna referencial, baseando-se na vivência de práticas de capacitação de condutores ambientais no sul do Brasil pelo Instituto Federal de Santa Catarina. Ele não pretende, de forma alguma, propor uma padronização de conteúdos e de estratégias metodológicas para cursos de capacitação nas mais diversas regiões brasileiras, nem mesmo propor estratégias e modelos empregados em outros países. Por outro lado, o trabalho visa propor uma base epistemológica para essa formação profissional, em prol de um turismo mais ecológico, comunitário, "humanizado" e identitário.

\section{Perfil dos Condutores Ambientais Locais}

Em nível federal, os condutores ambientais locais são reconhecidos pela Instrução Normativa 08/2008 do ICMBio, a qual considera 
(...) condutor de visitantes a pessoa cadastrada pelo órgão gestor da unidade de conservação, que recebeu capacitação específica e que é responsável pela condução em segurança de grupos de visitantes aos locais permitidos, desenvolvendo atividades interpretativas sobre o ambiente natural e cultural visitado, além de poder contribuir para o monitoramento dos impactos socioambientais nos sítios de visitação.

Complementando o perfil descrito pela IN, ressalta-se que o condutor ambiental local é um profissional da área do turismo e auxiliador da sensibilização e conservação ambiental, capaz de conduzir visitantes em diversos atrativos (sítios) turísticos naturais de sua localidade de ação - protegidos ou não. Contudo, dentro das Unidades de Conservação da Natureza, os condutores devem ser cadastrados e receberem autorizações dos órgãos gestores para atuação no local. Ressalta-se que, para o seu reconhecimento, os condutores normalmente realizam cursos de capacitação profissional, oficinas ou processos de certificação de saberes, os quais avaliam ou promovem o desenvolvimento de conhecimentos, habilidades, competências e atitudes inerentes à função que executam.

O condutor é preferencialmente um integrante do entorno ou da localidade onde atua, um "nativo", apresentando conhecimentos vivenciais do meio biológico e cultural do que interpreta, o que o difere dos demais sujeitos do "mercado" turístico. Muitos condutores ambientais são "mateiros", extrativistas, pescadores ou ex-caçadores. Ao ser um membro da comunidade e um retrato da cultura local, o condutor em si também pode ser visto como um atrativo turístico, promotor de um intercâmbio cultural. Programas de turismo de base comunitária podem vislumbrar nos condutores locais perspectivas de sua concretização atualmente muito idealizada, mas ainda pouco concebida.

Sua área geográfica de atuação restringe-se a um atrativo turístico natural específico - como uma Unidade de Conservação (ou seu fragmento) ou mesmo um ecossistema local. Analogicamente, o condutor pode ser considerado como o especialista da interpretação turística, aquele que conhece profundamente a área que atua, além de utilizar-se de conhecimentos científicos, etnobiológicos e de aspectos culturais locais em suas interpretações, com a promoção de um diálogo de saberes.

O condutor é um promotor da sensibilização ecológica e cultural do visitante, utilizando-se da educação ambiental. Entretanto, deve-se ter em mente - especialmente em cursos de 
capacitação - que o condutor não é meramente um "professor de campo". Como profissional do eixo turístico, o condutor deve preocupar-se com a conservação dos ecossistemas locais, com o bem-estar das populações envolvidas, não se esquecendo do bem-estar e da satisfação dos visitantes. Caso este último aspecto não seja considerado - especialmente quando práticas educativas são empregadas de forma excessiva ou desestimulante, programas ecoturísticos poderão fadar-se ao fracasso. Isso porque o visitante não deseja encontrar apenas informações e práticas de sensibilização, mas também momentos de lazer.

O condutor é fundamentalmente um profissional que conduz pessoas em ambientes naturais protegidos e de interesse paisagístico. Além disso, ele auxilia órgãos ambientais e culturais no monitoramento das áreas que atua, sendo esta ação uma de suas contrapartidas às áreas públicas das quais retira o seu sustento.

Algumas pessoas sobrepõem erroneamente a função de condutor ambiental local com a de guia de turismo. Contudo, são profissionais distintos, que se complementam, apesar de poderem trabalhar em torno no mesmo tema. O guia de turismo normalmente fornece informações mais generalistas, uma vez que, no Brasil, é capacitado para atuação regional (estadual) e nacional. O condutor ambiental local, por sua vez, apresenta conhecimentos ecológicos vivenciais, específicos da localidade que atua, além de ser um representante ou difusor da cultura local. Além disso, é um agente autorizado por órgãos ambientais para atuar conduzindo visitantes em Unidades de Conservação da Natureza e em outros ambientes naturais protegidos, o que o distingue de qualquer outro profissional da área. Guia e condutor não devem ser vistos como concorrentes, mas como profissionais que se complementam e que diversificam roteiros turísticos (FERREIRA; COUTINHO, 2010).

\section{O Papel de Condutores Ambientais Locais no Ecodesenvolvimento Turístico}

Os condutores ambientais locais - representantes e valorizadores da cultura local, além de promotores da conservação dos ecossistemas visitados e de uma nova consciência ambiental dos visitantes - podem ser vistos como uma das vias promotoras do ecodesenvolvimento turístico, em contraposição ao turismo de massa. 
Apesar do turismo de massa ser considerado uma das atividades que mais contribuem economicamente para diversas cidades litorâneas brasileiras, isso não corresponde diretamente ao desenvolvimento social local que a atividade promove. De acordo com Mello (2007), "não se pode admitir que o desenvolvimento de uma sociedade seja entendido como o binômio formado pelo crescimento econômico e pela modernização tecnológica, ou seja, o desenvolvimento econômico" - pois o desenvolvimento deve auxiliar na superação dos problemas sociais, em cujo âmbito uma sociedade se torna para seus membros mais justa e legítima. Deve se levar em conta que "a economia não é tudo sem a eficácia social" (RODRIGUES, 1997, p.10).

Conforme Vieira (2005), ecodesenvolvimento pode ser compreendido como uma política ambiental preventiva e proativa, que estimula a construção participativa e integrada de novas estratégias de desenvolvimento, com a corresponsabilidade das populações locais.

No nível macroeconômico, as políticas de ecodesenvolvimento podem ser abordadas como uma tentativa de restabelecer a harmonia perdida entre desenvolvimento e meio ambiente, onde o Estado se torna responsável pela implantação de um conjunto coerente de medidas capazes de orientar e articular as iniciativas que emergem no nível local (VIEIRA, 2005, p.348).

Dentro dessa visão, o turismo deve ser encarado como importante vetor de desenvolvimento de base local, contemplando principalmente as potencialidades endógenas, sendo pensado e estruturado para contribuir para a melhoria de vida da comunidade receptora, assim como para a conservação dos recursos naturais locais - ou seja, para uma sustentabilidade socioambiental local (MELLO, 2007).

O condutor ambiental local, por sua vez, deve apresentar funções essenciais na estruturação desse novo turismo, um turismo que internaliza custos ambientais e sociais em seu desenvolvimento.

\subsection{Educação ambiental e promoção do ecoturismo}

Um dos aspectos relevantes a ser proporcionado aos visitantes de atrativos turísticos naturais é a capacidade de maravilharem-se e sensibilizarem-se com aspectos naturais aparentemente triviais - um feito difícil de ser alcançado na atual sociedade, fundamentada na padronização 
e na valorização de bens de consumo. O condutor é, nesse sentido, um educador socioambiental, que não irá simplesmente professar conhecimentos, mas induzir sujeitos a compreensões ecológicas efetivas através de vivências. Ao ser um agente promotor do ecoturismo, ele deverá sensibilizar o visitante para questionar seus valores e seu modo de vida em prol da conservação e preservação ambiental, assim como para respeitar e valorizar a cultura local.

Utilizando-se da educação ambiental, o condutor tem um papel fundamental na significação da jornada em detrimento do destino. Quando se interpreta os aspectos integrantes da paisagem e quando se relaciona com o visitante de uma forma mais humana e pessoal, todo o percurso passa a ser mais significativo e prazeroso. Normalmente roteiros de condução convencionais são focados no destino, desconsiderando que o momento de convivência entre visitante, condutor e paisagem é mais significativo durante o percurso - período mais longo da visitação. O destino normalmente resume-se a um curto momento de contemplação, interpretação e de fotos, isso quando satisfaz as expectativas dos visitantes.

Verifica-se que o condutor, ao promover o ecoturismo através da educação ambiental, diferese de uma gama de outros profissionais que também atuam em ambientes naturais - como condutores de turismo de aventura, os quais normalmente apresentam como foco a atividade esportiva em detrimento à interpretação e sensibilização ambiental.

\subsection{Interpretação ambiental por meio do diálogo de saberes}

O condutor ambiental local tem a obrigação de promover um diálogo de saberes em suas atividades interpretativas, tanto pelo seu comprometimento social com a comunidade local e respeito ao etnoconhecimento associado, como pelo conhecimento científico, normalmente adquirido em cursos de capacitação. Além disso, seu sucesso profissional pode estar atrelado à promoção desse diálogo.

Dentro de uma perspectiva turística e conforme MacCannell (1976 apud ARAÚJO, 2001), os turistas anseiam por ir além do que é normalmente mostrado dos lugares que visitam, pois não se satisfazem com um conhecimento de fachada, superficial - querem penetrar nos bastidores dos lugares por onde andam. Uma das formas de acessar os bastidores locais é ter acesso ao etnoconhecimento local, especialmente aquele que reflete uma identidade cultural do território. 
O etnoconhecimento é atraente, pois é constituído essencialmente pelas significações humanas. Como o ser humano é um ser "simbolizado", a simples interpretação física ou científica da natureza pode não lhe ser suficiente, especialmente em um mundo de múltiplas identidades. Por outro lado, o contato com outros povos, culturas e significações da natureza auxilia no processo de humanização do próprio homem. Isso porque, conforme Caetano (2008, p.282), “o homem já não vive num universo puramente físico, mas num universo simbólico". "A atividade física parece retroceder proporcionalmente, à medida que avança a atividade simbólica do homem. Quanto mais complexas as redes simbólicas que representam a sua vida, mais humanizado ele se torna".

Mesmo assim, a interpretação ambiental não pode ser baseada apenas no senso comum ou em conhecimentos científicos - mas no intercâmbio entre esses dois saberes, uma vez que o ambiente é demasiadamente complexo para ser compreendido sob a ótica de um único prisma. Dentro desse contexto e segundo Leff (2001, p.183-184):

A interdisciplinaridade ambiental ultrapassa o campo científico, acadêmico e disciplinar do conhecimento formal certificado e se abre para um diálogo de saberes, em que se dá o encontro entre o conhecimento codificado das ciências e os saberes organizados pela cultura (...). O saber ambiental nesse contexto é um saber identitário, conformado por e arraigado em identidades coletivas que dão sentido a racionalidades e práticas culturais diferenciadas. Ele implica um rompimento com o conhecimento universal e disciplinar que implanta o regime de dominação da natureza por meio da ciência e que se situa acima dos saberes e identidades culturais (...). O saber ambiental forjase no encontro (enfrentamento, entrecruzamento, hibridação, complementação e antagonismo) de saberes diferenciados por matrizes de racionalidade-identidade-sentido que respondem a estratégias de poder pela apropriação do mundo e da natureza (...). No entanto, o saber ambiental não suplanta o regime da socialização do conhecimento pela individuação de um saber "pessoal".

Verifica-se aqui um dos grandes entraves de cursos de capacitação de condutores: a promoção e valorização de um diálogo de saberes. Fazer relação entre conhecimentos com bases epistemológicas distintas é desafiador. Professores dominam parcialmente o conhecimento científico, enquanto que os "doutores" do etnoconhecimento são os integrantes da comunidade. Uma aproximação se faz necessária. Para os acadêmicos, é interessante frisar que a cultura e os saberes locais são fatores de atração do visitante, que quer saber como vive e pensa a comunidade local. 
Um dos papéis que diferenciam o condutor ambiental de outros profissionais do turismo é o uso respeitoso e contextualizado dos saberes locais e memórias populares em suas interpretações, sem sua descaracterização ou banalização frente aos conhecimentos científicos. Assim, o condutor demonstra sua postura ética com a comunidade com a qual atua e que, de certa forma, ele representa. Em suas interpretações, conhecimentos não devem ser afirmados - e sim contextualizados, uma vez que qualquer realidade é "relativa".

Vale ressaltar que, conforme o Manifesto Ecológico Brasileiro, a perda da diversidade cultural no Brasil atrela-se ao desenvolvimento da cultura de massas, a qual é severamente criticada. A padronização em massa exige a padronização dos produtos, e o consequente condicionamento para o consumo leva à uniformidade cultural. Soçobram tradições e extingue-se o colorido local (DIEGUES, 2008). Por outro lado, de acordo com Sahlins (2008), nas últimas décadas vários povos têm contraposto conscientemente sua cultura às forças do imperialismo ocidental, como uma possibilidade de, não apenas marcar identidade, mas de retomar o controle do próprio destino. Para o autor, é preciso reconhecer o desenvolvimento simultâneo de uma integração global e de uma diferenciação local como duas tendências constitutivas da realidade.

Em oposição ao global, o local acaba recobrando a importância das ações e experiências microespaciais. Na corrida em busca do conhecimento e dos saberes das populações tradicionais, o espaço é fator de singularidade. Cada lugar é portador de uma identidade própria, conhecida e interpretada à luz das experiências de seus habitantes (SANTOS; PEREIRA; ANDRADE, 2007).

\subsection{Envolvimento da comunidade local}

Todo e qualquer programa de visitação com base no ecodesenvolvimento deve incluir a comunidade em suas práticas, constituindo-se em um turismo de base local que proporciona efetivamente um desenvolvimento social. Nesse contexto, o condutor ambiental tem um papel essencial, com a valorização de atividades tradicionais sustentáveis e o estímulo ao envolvimento comunitário. Valorizar o artesanato local, a comida típica da comunidade e o transporte realizado por pescadores artesanais são exemplos concretos desse papel.

Ao envolver a comunidade e estimular a geração de renda, o condutor deve preocupar-se em não descaracterizar aspectos culturais locais com a cobrança de padrões pré-estabelecidos 
dentro do trade turístico. Ele ainda deve educar o visitante para que conceba a existência de diferentes formas de desenvolvimento, as quais não se constituem em estágios progressivos (LARAIA, 2002). Ou seja, uma comunidade que viva da produção primária pode não almejar torna-se uma complexo industrial ou comercial, e isto não significa que seja menos desenvolvida. Esta educação tem a finalidade de fortalecer o respeito do visitante pela forma de organização da comunidade visitada.

O encontro cultural entre visitantes e "nativos" é mais um dos papéis dos condutores. Nesse intercâmbio, ambos os lados devem aprender e respeitar as diferenças, pois é nesse confronto que surge o crescimento - não em prol de sua padronização, mas de sua tomada de consciência e valorização.

Como forma de contextualizar e valorizar aspectos culturais locais aos visitantes, o condutor poderá apresentar memórias locais e conhecimentos históricos em suas interpretações. Pode ainda resgatar ações passadas na forma de "museu vivo" ou encenação: como apresentar um antigo engenho em funcionamento movido a carro de boi. Contudo, o condutor não pode interpretar o "espetáculo" como a realidade local. Caso isso aconteça - com a perspectiva de forjar um identidade local não mais encontrada, o condutor estará desrespeitando e negando a cultura local vigente. O condutor deve contextualizar o passado para a compreensão do presente.

Para um maior envolvimento da comunidade local, medidas públicas de capacitação de condutores ambientais devem priorizar a seleção de pessoas que residam no entorno de Unidades de Conservação ou que apresentem uma vivência ou dependência econômica direta da exploração de recursos naturais (como comunidades tradicionais extrativistas). Com isso, o próprio sistema de capacitação estará estimulando o turismo de base comunitária, possibilitando que "nativos" sejam beneficiários e agentes do ecoturismo local.

\subsection{Respeito à "estética natural" e humanização da condução}

Apesar do termo "estética" apresentar diversas definições e estar atrelado à construção simbólica humana - ou seja, à conceituação do belo, o termo "estética natural" aqui proposto define-se como configurações naturais encontradas em sistemas ecológicos em equilíbrio. Esta estética natural, por sua vez, é definida, delineada e "autoarquitetada" para chegar a um equilíbrio dinâmico, a um sistema circular e sustentável, e sua "engenharia" e autogestão por 
si só poderiam ser considerados padrões estéticos exemplares e espetaculares. É uma desordem que se auto-organiza.

Mas, o que é belo para o homem da atualidade? Este homem, que vive no meio urbano e num sistema no qual o capital, os bens de consumo e o status social são os veículos promotores de sua felicidade, não consegue deleitar-se por muito tempo - a não ser durante os segundos da foto - com a beleza ou estética natural presente, por mais "espetacular" que seja. Por que motivo isso ocorre? Uma das razões reside no fato de diversos componentes da paisagem não apresentarem significado para esse homem. Ou seja, quando se visualiza os aspectos físicos do mundo material, não se vê apenas sua imagem, mas especialmente as significações e construções simbólicas construídas para cada um. Dentro dessa perspectiva, o homem não pode significar ou sensibilizar-se com algo que não conhece - nesse caso, o ecossistema local. Verifica-se assim a necessidade de uma educação ecológica do visitante em prol de uma nova significação do ambiente e de um novo referencial, e os condutores tem o papel de sensibilizá-lo para tornar padrões ecológicos e culturais identitários em padrões estéticos a serem respeitados ou mesmo almejados. Assim, uma vegetação aparentemente percebida pelo visitante como um "matagal" sem função, pode então ser ressignificada como uma vegetação de transição, com sua beleza própria, capaz de criar condições sem as quais um ecossistema em equilíbrio não poderia estabelecer-se.

Na procura dessa estética natural em práticas de condução, há um questionamento relacionado à infraestrutura: o que é necessário existir em ambientes naturais protegidos para que a condução se efetive e seja significativa? Muitos apontam a necessidade de uma infraestrutura física mínima, como placas informativas, centros de visitação, áreas recreativas, trilhas demarcadas, entre outras. Contudo, o que o visitante vem buscar fora do seu meio urbano e padronizado? A previsibilidade? O padrão verificado em outros países? Ver exatamente a foto da revista? Será que o visitante já não está enfadado com os padrões encontrados em sua vida? Será que ele não busca novas experiências, o imprevisível ou um referencial de ambiente sem a interferência direta do animal "homem"? Caso esse seja o propósito (pois o contrário é o seu cotidiano), quanto mais alterada propositalmente é uma trilha em prol da “infraestrutura turística", mais ela se distancia do objetivo. Todavia, a infraestrutura essencial em prol da conservação ambiental e da minimização do impacto de práticas de condução não 
deve ser relevada, assim como a infraestrutura para garantia da segurança do visitante, analisando-se caso a caso.

Nesse sentido, poder-se-ia considerar como infraestrutura básica para práticas de condução a "infraestrutura humana", o próprio condutor, capaz de promover o ecodesenvolvimento turístico local, direcionando a experiência do visitante em prol da sensibilização ambiental e da conservação dos ecossistemas visitados, através de um relacionamento baseado na afetividade, no respeito e na cordialidade - um possível "remédio" para a atual "sociedade dos indivíduos".

Ressalta-se aqui a necessidade de uma maior humanização em práticas de condução, de um profissional "em primeira pessoa", que além de transmitir informações sobre os locais visitados, transmite um pouco de si mesmo de uma forma respeitosa, considerando o perfil dos visitantes. Verifica-se a necessidade da dissociação entre profissionalismo e impessoalidade. $\mathrm{Na}$ atual sociedade, profissionais são valorizados por utilizarem-se do intelecto em detrimento dos sentimentos. Contudo, deve se ter em vista que o ser humano é complexo, constituído por diversos aspectos, sendo que a valorização de sua fragmentação e negação de uma parte é, de certa forma, uma maneira de rejeitá-lo e de padronizar relacionamentos, os quais deveriam ser peculiares. Ao tornar-se pessoal, o condutor torna-se também um profissional único e autêntico, capaz de promover momentos irreprodutíveis e identitários.

\subsection{Monitoramento e manutenção dos ambientes naturais protegidos}

Como já mencionado, o condutor ambiental local tem o comprometimento de auxiliar órgãos públicos ligados ao meio ambiente e à cultura no monitoramento de ecossistemas locais e do patrimônio cultural visitado. Essa é uma das suas contrapartidas ambientais e sociais, promovendo a perpetuação e manutenção de seu local de atuação.

Ele não deve ser visto como o agente fiscalizador, mas como seu auxiliar, fazendo com que a comunidade se inteire da legislação ambiental vigente e de políticas públicas relacionadas, internalizando-as positivamente. Para isso, cursos de capacitação de condutores devem incluir assuntos relacionados à legislação ambiental e patrimonial brasileira. As instituições envolvidas nas atividades formativas devem ainda articular e fomentar a aproximação entre a 
comunidade e os condutores locais com os órgãos fiscalizadores, para que se visualizem como parceiros, e não como rivais - trabalhando para um objetivo em comum.

\subsection{Promoção da economia solidária}

O condutor ambiental local, normalmente um profissional autônomo, deve atuar na organização da categoria, visando ao aperfeiçoamento das suas atividades e contribuindo para a formulação de políticas públicas em turismo e meio ambiente.

Ao ser um promotor do ecodesenvolvimento turístico, o condutor deve se inserir em empreendimentos justos socialmente e que visem à sustentabilidade, nos quais o lucro e a competitividade não são os únicos ou mais importantes fatores considerados. Dentre estas formas de empreendimentos pode-se destacar o associativismo e o cooperativismo com base na economia solidária (ECOSOL).

Segundo o Ministério do Trabalho (MTE/BRASIL, 2011), a economia solidária pode ser compreendida como uma forma diferente de produzir, vender e comprar, sem explorar os outros, tirar vantagem ou destruir o ambiente - com a promoção de um comércio justo e um consumo solidário. Para trabalharem de acordo com os princípios da economia solidária, os condutores ambientais devem promover a cooperação em prol de objetivos comuns, da propriedade coletiva de bens e da partilha de resultados e responsabilidades, além de autogestionar os processos de trabalho, de forma a viabilizar economicamente a sua atividade, considerando critérios de eficácia ao lado de aspectos sociais e ambientais. A promoção da economia solidária implica na reversão da lógica capitalista ao se opor à exploração do trabalho e dos recursos naturais, considerando o ser humano na sua integralidade como sujeito e finalidade da atividade econômica (MTE/BRASIL, 2011).

Os princípios da economia solidária devem ser trabalhados em cursos de capacitação de condutores e sua prática fomentada e orientada. O Campus Florianópolis Continente do IFSC, a exemplo, além de capacitar condutores locais, promove a incubação de associação de base solidária para os condutores formados, valendo-se do discurso e da prática para uma transformação social. 


\section{Expectativas Sociais}

A perspectiva de uma gestão mais participativa e de um turismo mais comunitário não deve ser um discurso empregado apenas na base de ação, mas na sua idealização e proposição. Como o presente trabalho propõe um perfil e funções a condutores ambientais locais, as expectativas de representantes de órgão públicos ligados ao meio ambiente, ao turismo e à educação, além das expectativas de representantes comunitários não poderiam ser desconsideradas. Tais relatos não serão discutidos, uma vez que seus autores são considerados co-autores do presente trabalho.

\subsection{Expectativas e visões de representantes de órgãos públicos}

“Com relação às unidades de conservação municipais de Florianópolis, o Departamento de Unidade de Conservação - DEPUC da FLORAM tem por expectativa, relativamente à formação de condutores ambientais locais, a qualificação na prestação de serviços de condução de estudantes, turistas e visitantes em geral pelos diferentes ambientes, preservados ou não, das unidades de conservação, no sentido de transmitir informações sobre a interpretação do ambiente percorrido, seus aspectos naturais, biodiversidade, importância ecológica, etc., assim como as modificações introduzidas pelo homem - seus aspectos positivos ou negativos. Esta é uma atividade complementar da maior importância para a gestão das unidades de conservação, no sentido de divulgar sua importância para a sociedade em geral, dentro de um processo mais amplo de educação ambiental associado ao lazer e ao turismo de qualidade. Da mesma forma, tende a valorizar o conhecimento empírico dos moradores de comunidades próximas a estas unidades de conservação, além de oportunizar a geração de trabalho e renda para as estas pessoas".

Danilo da Silva Funke - Biólogo / Chefe do Departamento de Unidades de Conservação da FLORAM Fundação Municipal do Meio Ambiente de Florianópolis / Conselheiro do CRBio $3^{\text {a }}$ Região / Membro dos Conselhos Consultivos da Estação Ecológica de Carijós, Reserva Biológica Marinha do Arvoredo e Parque Nacional da Serra do Itajaí (UCs federais); Parque Estadual do Rio Vermelho (UC Estadual); e Parque Urbano do Morro da Cruz (UC Municipal) / Data do relato: 26/08/2011.

"Dentre as finalidades das Unidades de Conservação (UCs) destaco a conservação da biodiversidade. A preservação deste patrimônio ambiental, na maioria das vezes de responsabilidade das instituições públicas, necessita de gestão qualificada. A implantação de 
uma UC compreende desde a previsão de estruturas adequadas até a seleção de pessoas capacitadas para exercerem funções que requerem conhecimentos especificos dos mais variados. Nestes termos, para uma gestão de excelência, a quantidade ideal de profissionais é elevada. Mesmo que a instituição responsável pela gestão possua todos estes profissionais em seu corpo técnico, geralmente não fazem parte de suas formações os conhecimentos cultural, tradicional e geográfico das UCs e seu entorno. Só se pode ter acesso a estes conhecimentos através das comunidades locais inseridas ou no entorno das UCs. Assim sendo, quando tratamos especificamente da implantação de turismo sustentável em Unidades de Conservação, que é um dos objetivos da maioria das categorias de UC elencadas pelo Sistema Nacional de Unidades de Conservação - SNUC, torna-se imprescindivel esse tipo de conhecimento, aliado aos conhecimentos técnicos e científicos oriundos das instituições gestoras e de ensino. Para reunir estes conhecimentos em um profissional, precisa-se de uma formação qualificada. Entendo que o Instituto Federal de Santa Catarina ministra de forma adequada os conhecimentos acima descritos, através do Curso de Capacitação de Condutores Ambientais Locais e, temos a expectativa que promova o envolvimento das comunidades locais na gestão destes espaços legalmente protegidos para a conservação da biodiversidade”.

Eduardo Mussatto - Filósofo / Supervisor de Unidades de Conservação da FATMA - Fundação Estadual do Meio Ambiente de SC / Chefe da APA Estadual da Vargem do Braço / Membro da Câmara Técnica de Compensação Ambiental, Membro Equipe Técnica de Controle e Erradicação de Espécies Exóticas em Unidades de Conservação / Representante da FATMA em Conselhos Consultivos de Unidades de Conservação federais e municipais / Data do relato: 27/08/2011.

"Penso que o condutor ambiental local tem uma atuação que se constrói na interface entre sociedade e ambiente. Isto é, seu papel social pressupõe a capacidade de conduzir visitantes e turistas em ambientes naturais, possibilitando uma (re)interpretação da natureza. Já seu papel ambiental se baseia na capacidade de promover formas de interação com o ambiente que levam em conta a importância de conhecê-lo para valorizá-lo e conservá-lo, tanto por ele próprio quanto pelos visitantes e turistas conduzidos. Neste sentido, um se imbrica no outro, ao ponto de se poder falar em "papel socioambiental". Por isto, sua formação deve incluir conhecimentos das ciências naturais e humanas. Ao mesmo tempo em que ele precisa conhecer aspectos da fauna, da flora e dos ecossistemas visitados, ele também precisa 
entender aspectos básicos da cultura local, assim como as características das pessoas ou dos grupos com os quais trabalha, suas necessidades e expectativas. Vale dizer que um condutor é também um "tradutor": da natureza, da cultura, dos bichos, das plantas, das pessoas e daquilo que resulta da interação entre estes componentes bióticos e abióticos dos ecossistemas visitados".

Luiz Otávio Cabral - Agrônomo / Doutor em Geografia / Coordenador de Cursos de Formação Inicial e Continuada do Campus Florianópolis-Continente do Instituto Federal de Educação, Ciência e Tecnologia de Santa Catarina (IF-SC) / Professor de Educação e Legislação Ambiental do IF-SC / Data do relato: 27/08/2011.

"O curso de condutores ambientais, disponibilizado pelo IF-SC na Baixada do Maciambu em Palhoça é uma importante ferramenta para melhoria da atividade turística nesta região. Bom, o turismo em Palhoça surgiu em meados da década de 80, em função da procura de visitantes por Florianópolis. Sem planejamento adequado, Palhoça surge para o cenário turístico como tantas outras cidades litorâneas, em função das suas belezas naturais em especial suas praias. Os moradores locais veem no turismo uma importante fonte de economia, mas é fundamental que estes mesmos moradores entendam que se faz necessário a manutenção da cultura local, bem como a conservação e preservação do meio ambiente natural. Atualmente se faz necessário inúmeras melhorias em infraestrutura para que o turismo possa ser uma fonte de renda nos doze meses do ano, não apenas em dois meses, como acontece hoje. Este curso possibilitará um olhar de outro angulo sobre o turismo, ou seja, fará com que o morador observe as várias possibilidades oportunizadas por esta atividade que é o turismo. É possivel que nem todos os condutores ambientais conduzam turistas em trilhas, porém é fato que serão sim multiplicadores deste novo olhar, desta nova consciência, buscando melhorar o quintal de sua casa e cobrar do poder público o que cabe a ele, bem como ao setor privado a sua contribuição".

Gicele Truppel - Bacharel em Turismo e Especialista em Gestão de Pessoas / Secretária de Turismo de Palhoça (2008) / Diretora Geral de Turismo Palhoça (2009/2010) / Superintendente da Região Sul e Turismo de Palhoça 2011 / Data do relato: 28/08/2011.

\subsection{Expectativas e visões de representantes comunitários}

"Primeiramente nossos objetivos como extrativistas, futuros condutores ambientais são de valorizar a cultura da comunidade local, a pesca artesanal, preservar a biodiversidade da RESEX do Pirajubaé e ajudar a população tradicional que sobrevive dos recursos pesqueiros 
da região, com geração de renda através do turismo. Com o desenvolvimento desde curso e com muita educação ambiental, queremos mostrar a importância do ecossistema dos Manguezais, sua função de estuário, berçário e reprodução de várias espécies. Através do turismo consciente, teremos condições de apresentar para o mundo a beleza natural de nossa Reserva Extrativista. Com visitas aos rios, contemplação das aves, trilhas ecológicas, passeios de barco, pescarias esportivas, apresentação dos apetrechos de pesca tradicionais, alem da gastronomia com pratos típicos preparados com berbigão, caranguejo, peixes, camarão, os visitantes serão bem vindos. Dessa forma esperamos aprender a maneira correta de conduzir os visitantes, saber diversificar as possibilidades de pontos de visitação, como elaborar um roteiro, questões de segurança, divulgação, propaganda, administração e principalmente os procedimentos para ser realizado um turismo de qualidade”.

Fabrício Gonçalves - Extrativista da Reserva Extrativista Marinha do Pirajubaé, Florianópolis, SC Brasil / Presidente da Associação Caminho do Berbigão / Data do relato: 27/08/2011.

"Frequentemente ouve-se dizer que nas últimas cinco décadas a ciência e a tecnologia se desenvolveram muito mais do que em toda existência humana anterior. Porém é notável e pode-se afirmar que essa importante e inegável conquista do homem lhe tenha proporcionado igual evolução no terreno da ética e da moral e igualmente lhe tenha trazido conforto em relação às demandas no tocante ambiental. Cientes desse fato moderno, os condutores ambientais precisam se distinguir não só pela capacidade de desenvolver conexões lógicas e racionais, mas também, pela capacidade de convívio saudável com a complexidade ambiental, incluindo o seu semelhante, que não se restringe somente a outro da sua espécie, mas com todos os seres vivos e não vivos, respeitando incisivamente as diferenças. Fazer imposições de condutas não é relevante, mas balizar sua condução em parâmetros éticos deve ser absoluto, pois que, o condutor ambiental, por natureza é um potencial formador de opinião, logo um potencial agente da educação ambiental para a ação consciente e integrada em cuja ação fortalecerá aos conduzidos o sentido de pertencimento e responsabilidade cósmica. Remetendo para o aspecto insular, mais precisamente para as comunidades da Barra do Sul, composta de Tapera, Caieira e Naufragados, o tratamento não poderá ser diferente. Aliás, o que escrevo nas linhas primeiras tem assentamento na minha vivência e existência no espaço físico geográfico deste Sul da Ilha de Santa Catarina, que muito me orgulha na qualidade de reduto cidadão, apesar das soberbas que nos foram e ainda nos são 
impostas em campos variados da anti-democracia, entre as quais algumas famigeradas investidas do Poder Público. Precisa-se romper com o atual modelo de desenvolvimento, muitas vezes escondido nas fumaças da moda do "desenvolvimento sustentável" e pôr-se grandemente para o uso racional dos recursos naturais e fazer o ecoturismo passar de vagos conceitos e princípios às suas consoantes práxis. O que está dito é extremamente sintético, portanto explicito e compreendo que há muito espaço para outras verdades advindas dos colegas condutores ambientais ou não, o que se faz justo e necessário reservar neste artigo lacunas para contribuições, incluindo o direito do contraditório, mas peço reciprocidade para o desejo participativo e simétrico do debate”.

Ademar Alarício do Espírito Santo - Membro da Comunidade da Caieira da Barra do Sul/Naufragados (Florianópolis-SC), localizada nas adjacências do Parque Estadual da Serra do Tabuleiro, APA do Entorno Costeiro, APA da Baleia Franca / Membro Fundador do Grupo de Jovens Santa Cruz (GJSC) / Representante do GJSC, credenciado no Programa Voluntários do Meio Ambiente Fiscal da FATMA - 1990 e 1991 / Membro Fundador da Sociedade Amigos da Barra do Sul (SABS) / Representante da SABS como delegado no Orçamento Participativo de Florianópolis - Gestão 1993/1996 / Associado da Associação. dos Moradores da Praia dos Naufragados (AMOPRAN) / Membro representante da Conselheira AMOPRAN na APA da Baleia Franca desde 2005 / Coordenador do Conselho de Pastoral Paroquial da Paróquia Nossa Senhora da Lapa desde 2005 / Participante do MOSAL - Movimento Coletivo que trata do Saneamento Alternativo para Florianópolis / Membro Fundador e Associado da UATAPÍ - Associação de Condutores Ambientais e Culturais da Grande Florianópolis / Data do relato: 24/08/2011.

\section{Relatos de Condutores Ambientais Locais}

O Campus Florianópolis-Continente do Instituto Federal de Santa Catarina capacita condutores ambientais locais desde o início de 2010, conforme os princípios e as concepções apontadas nesse trabalho. Para análise geral dos resultados alcançados, são apresentados relatos de condutores sobre perspectivas e modificações pessoais e profissionais conferidas pelo curso.

"Meu nome é Rodrigo, conhecido como Digão no Rio Vermelho, moro próximo ao Parque Estadual do Rio Vermelho, e quando eu cheguei aqui, e a forma como eu cheguei aqui, a forma que eu cheguei era como se tivesse com o vento, pra lá e pra cá, sem ter pra onde ir, quando os outros perguntavam pra mim: “No que que tu é profissional?”, eu olhava pros outros: "Eu não sei, eu faço de tudo um pouquinho, vendo pão de mel na rua, sou ambulante 
no verão, sou jardineiro durante o ano, me viro..." E esse curso me deu a oportunidade de dizer pros meus amigos: Eu sou um condutor ambiental. “Qual é a sua profissão?” Eu sou um condutor ambiental! (Bateu no peito uma felicidade muito grande, de ter essa oportunidade de estudar). Fazia muitos anos que eu não tinha conhecimento com lápis, com caderno, com caneta. Eu sempre queria trabalhar braçal, era uma necessidade, eu cheguei aqui eu tinha que trabalhar, não tinha outra coisa pra eu fazer, eu escolhi trabalhar porque eu tinha que construir a minha casa, pra eu ter onde morar, e de repente, apareceu a oportunidade, muitos me ajudando, a ficar com a minha filha, pra eu poder estar aqui estudando, cumprindo meus horários (...) tendo conhecimentos que eu nunca imaginava, técnicos. Eu tinha o conhecimento popular! "Aquilo ali, uma oficina lítica, parecia uma tampinha de privada, a forma como o pessoal falava, coisa da rua, não sabia o que era aquilo! Hoje, eu, Rodrigo, falo que este curso modificou a minha vida, deu um horizonte diferente, conheci pessoas legais, com várias formações, que me ajudaram. Me ajudam, as vezes, só de escutar eles falarem! ...então, esse curso foi um presente.! E ainda vou querer aprender mais. Esse curso foi o inicial, pra eu me aprimorar mais... Eu quero agradecer, de coração, me abriu um novo caminho, eu entrei aqui com medo de falar, e hoje, meus parentes me ligam dizendo : "Que bom que ta estudando!" Porque eu já tive um momento de rua, fazia coisa errada. E hoje eu to feliz, vou poder conduzir pessoas, ou, pelo menos fazer uma coisa que eu gosto".

Rodrigo Ramirez - Condutor Ambiental Local da Ilha de Santa Catarina (2010) / Morador do entorno do Parque Estadual do Rio Vermelho (Florianópolis/SC) / Data do depoimento: junho de 2010.

"Os ensinamentos do curso estão sendo colocados em prática a todo o momento. As pessoas notam a diferença na condução. Estamos revolucionando o modo de conduzir... Digo isso porque fui o mais citado nas avaliações dos hóspedes por boa postura, ética e atenções dispensadas. Agora dou palestras sobre Educação Ambiental e Reciclagem nas células do hotel".

Pércio Renato Souza dos Santos - Condutor Ambiental Local da Ilha de Santa Catarina (2010) / Monitor da Ilha do Campeche (Florianópolis-SC) / Data do depoimento: junho de 2011.

"Meu nome é Altamiro e eu conheço a Ilha há algum tempo, mas confesso que não conhecia a Ilha pelas entranhas, pelos trajetos que a gente fez. Eu conhecia a Ilha de outra maneira, pela estrada normal. E fiquei maravilhado! Foi uma oportunidade única”. 
Altamiro Valverde Filho - Condutor Ambiental Local da Ilha de Santa Catarina (2010) / Data do depoimento: junho de 2010.

"Eu tô achando o curso muito bom... noventa por cento do que eu estou aprendendo aqui eu estou aplicando no trabalho já... em relação ao que muda, acho que é muito mais segurança na hora de atuar, na hora de se apresentar porque até então não se tinha uma formação né, reconhecida pra isso, e eu senti uma diferença muito grande nesse sentido, na segurança de atuar e de se apresentar ao grupo".

Luana Wirth - Condutora Ambiental Local da Ilha de Santa Catarina em formação (2011) / Trilhas da Ilha Educação Ambiental e Ecoturismo / Data do depoimento: junho de 2011.

Bom, o que eu esperava do curso... eu vim esperando uma coisa e me surpreendi... eu achava que a gente ia ter muito mais vivência em campo e aprendi que, o que eu tinha aqui na minha cabeça que ah... muita teoria... e na prática... e me surpreendi que teoria é muito importante na prática; se eu não tivesse a teoria a gente não estaria na prática como a gente tá no campo olhando com os olhos que eu já vejo bem diferentes de antes. O ponto positivo é que é uma nova área para todo mundo né... nem todo mundo trabalhava com isso...

Maria José Passarelli Madureira - Condutora Ambiental Local da Ilha de Santa Catarina em formação (2011)/ Moradora do Entorno do Parque Estadual do Rio Vermelho (Florianópolis/SC) / Data do depoimento: junho de 2011.

"Então, só pra concluir, a Maria que fazia as trilhas de antes, não é a mesma Maria de agora!"”.

Maria de Lourdes Prá da Silva - Condutora Ambiental Local da Ilha de Santa Catarina (2010) / Educadora Ambiental da COMCAP (Companhia de Melhoramentos da Capital - Florianópolis/SC) / Data do depoimento: junho de 2010.

\section{Considerações finais}

Espera-se que os profissionais envolvidos em políticas públicas voltadas à promoção ecoturística e aqueles ligados efetivamente à capacitação de condutores ambientais locais visualizem nesses profissionais uma estratégia capaz de promover efetivamente um turismo ecológico, identitário e justo, configurando-se em um turismo de base comunitária. 


\section{Agradecimentos}

Agradecemos todos os parceiros envolvidos nesse trabalho, direta ou indiretamente, como representantes de órgãos públicos, servidores do Campus Florianópolis-Continente do IF-SC, condutores ambientais e alunos em capacitação. Em especial, agradecemos as diversas comunidades que mantêm características culturais identitárias e que vivem em harmonia com ecossistemas locais, sem as quais não seria possível idealizar e propor um novo turismo.

\section{Referências}

ARAÚJO, S. M. Artifício e autenticidade: o turismo como experiência antropológica. In: Turismo e identidade local: uma visão antropológica. Coleção Turismo, Campinas, SP: Papirus, 2001. p.49-63.

CAETANO, M. J. Ética e meio ambiente: reflexões sobre os lugares do homem na contemporaneidade. In: Saberes ambientais - desafios para o conhecimento disciplinar. Belo Horizonte: Editora UFMG, 2008. p.180-192.

DIEGUES, A. C. O mito moderno da natureza intocada. 6 ed., São Paulo: HUNCITEC / NUPAUBUSP/CEC, 2008. 198p.

FERREIRA, L. F. Reunião de trabalho sobre oferta de educação profissional em turismo e hospitalidade pela Rede Federal de Educação Profissional e Tecnológica. Florianópolis: PROECOTUR/MMA/BRASIL, 2008.

FERREIRA, L. F.; COUTINHO, M. C. B. Ecoturismo: a importância da capacitação profíssional do condutor ambiental local. In: Gestão ambiental e sustentabilidade no turismo. Barueri, SP: Manole, 2010. p.349-381.

LARAIA, R.B. Cultura, um conceito antropológico. Rio de Janeiro: Jorge Zahar, 2002.

LEFF, E. Saber ambiental: do conhecimento interdisciplinar ao diálogo de saberes. In: Epistemologia ambiental. São Paulo: Cortez, 2001. 240p.

MELLO, L. A. Análise reflexiva acerca da relação entre turismo e desenvolvimento local: bases conceituais. Revista Espaço Acadêmico, Nº 72, 2007.

MMA/BRASIL. Programa Nacional de Ecoturimo / Programa de Revitalização da Bacia Hidrográfica do Rio São Francisco: oficina "Possibilidades para Regulamentação da Atividade de Monitoria Ambiental em Unidades de Conservação. São Paulo: MMA / Secretaria de Políticas para o Desenvolvimento Sustentável, 2006. 33p.

MMA/BRASIL. Ecoturismo de base comunitária. 2011. Disponível em: <www.mma.gov.br>. Acesso em: agosto de 2011.

MMA/PROECOTUR. Reunião de planejamento - 2009 - Capacitação. Seminário, Brasília: PROECOTUR/MMA/BRASIL, 2009.

MTE/BRASIL. O que é economia Solidária. 2011. Ministério do Trabalho - Brasil. Disponível em: $<$ http://www.mte.gov.br/ecosolidaria/ecosolidaria_oque.asp>. Acesso em: agosto de 2011.

MTur/BRASIL. Guia de turismo e condutor ambiental - Legislação Correlata (MEC - MMA - MTE - MRE - MJ). Brasília (DF): CGST/Ministério do Turismo, 2008. 
RODRIGUES, A. B. Turismo e desenvolvimento local. São Paulo: Hucitec, 1997.

SANTOS, A. L. S.; PEREIRA, E. C. G.; ANDRADE, L. H. C. A construção da paisagem através do manejo dos recursos naturais e a valorização do etnoconhecimento. In: Povos e paisagens: etnobiologia, etnoecologia e biodiversidade no Brasil. Recife: NUPEEA/UFRPE, 2007. p.61-74.

SAHLINS, M. O "pessimismo sentimental" e a experiência etnográfica: por que a cultura não é um objeto em via de extinção. (Partes 1 e 2). Disponível em: <http://poars.1982.files.wordpress.com 2008/03/pdf>. Acesso em: agosto de 2011.

VIEIRA, P. F. Gestão de recursos comuns para o ecodesenvolvimento. In: Gestão integrada e participativa de recursos naturais - conceitos, métodos e experiências. Florianópolis: Secco/APED, 2005. p.334-377.

Recebido em: 16/09/2011

Aprovado em: 01/12/2011 